\title{
O ALTO REPRESENTANTE-GERAL DO MERCOSUL: ORIGENS, CARIZ E EXTINÇÃO'
}

\author{
THE HIGH GENERAL REPRESENTATIVE OF MERCOSUR: ORIGINS, \\ NATURE AND EXTINCTION
}

DOI: $\underline{10.5380 / \operatorname{cg} . V 10 i 3.81904}$

Luan Olliveira Pessoa ${ }^{2}$

\begin{abstract}
Resumo
As relações externas do Mercosul dispuseram de um cargo/órgão de representação externa a partir do fim de 2010: o Alto Representante-Geral do Mercosul (ARGM). Ele recebeu numerosas atribuições em assuntos intraMercosul e nas relações externas. E era estimado como "a cara" do Mercosul no discurso diplomático brasileiro e direcionado a melhorar a projeção do Mercosul. Contudo, sua extinção ocorreu logo no início de 2017, após o conturbado ano de 2016. A partir da compreensão de projetos políticos de construção de região, esse artigo visa ocupar o espaço incipiente sobre o ARGM na pesquisa relativa ao "novo Mercosul" apresentando um estudo da criação à rápida extinção. Sem seguir a via canônica de negociar com terceiros rumo ao livre comércio, as vinculações promovidas nas atividades do órgão nas relações externas eram políticas, muito mais que comerciais. Entrevistas, pesquisas documental e bibliográfica permitem sugerir que a criação e as atividades do ARGM se desenvolveram em direção à América do Sul e em adequação ao "novo Mercosul" até perder tal condição com a vigência de outro projeto político regional, o "Mercosul do século XXI".
\end{abstract}

Palavras-Chave: Alto Representante-Geral do Mercosul; Novo Mercosul; Relações externas; Mercosul; Regionalismo.

\begin{abstract}
Mercosur's external relations had an external representative position/body from the end of 2010: the High General Representative of Mercosur (ARGM). He received numerous assignments in intra-Mercosur affairs and in external relations. And it was considered as "the face" of Mercosur in Brazilian diplomatic discourse and oriented to improve Mercosur's projection. However, its extinction occurred at the beginning of 2017, after the troubled year of 2016. Based on the understanding of political projects for region building, this article aims to occupy the incipient space on the ARGM in the research related to the "new Mercosur", presenting a study from its creation to this quick extinction. Without following the mainstream of negotiating with third parties towards free trade, the links promoted in the agency's activities in external relations were political, much more than commercial. Interviews, documentary and bibliographical research support the suggestion that the creation and activities of ARGM developed towards South America and in adaption to the "new Mercosur", until it lost this condition with the strengthening of another regional political project, the "Mercosur of the 21st century".
\end{abstract}

Keywords: High Representative General of Mercosur; New Mercosur; External relations; Mercosur; Regionalism.

\footnotetext{
${ }^{1}$ Este artigo está licenciado sob a Licença Creative Commons Attribution (CC BY 4.0), sendo permitido o compartilhamento com reconhecimento da autoria e publicação inicial nesta revista.

${ }^{2}$ Doutorando no Programa de Pós-Graduação em Relações Internacionais da Universidade Federal da Bahia. Pesquisador do Observatório de Regionalismo. E-mail: luan.op@outlook.com. ORCID: https://orcid.org/o0o0-0001-9595-1324.
} 


\section{INTRODUÇÃO}

Reunido em dezembro de 2010, o Conselho do Mercado Comum (CMC), órgão máximo do Mercado Comum do Sul (Mercosul), criou o Alto Representante-Geral do Mercosul (ARGM), fruto de proposta brasileira. O CMC conferiu ao novo órgão numerosas atribuições relativas à "articulação política, formulação de propostas e representação das posições comuns dos Estados-membros” (FIGUEIREDO, 2012). Elas eram relevantes em assuntos intra-Mercosul (dimensão interna) e nas relações externas (dimensão externa) (CABALLERO, 2013) e tinham por princípios “o interesse geral do Mercosul e o aprofundamento do processo de integração”, fixados na decisão criadora.

Ao Mercosul dispor de um cargo/órgão de representação externa, o discurso diplomático brasileiro o distinguiu como "a cara" do Mercosul (ARSLANIAN, 2012; PATRIOTA, 2012; SCOFIELD, 2010) e o preâmbulo da decisão criadora manifestou o anseio por "melhor projeção do Mercosul” a partir do novo órgão.

Na história política do Mercosul, o ARGM foi criado durante o período chamado "novo Mercosul” (RAMOS, 2015), distinguido justamente pela conversão da política em princípio regulador da vida social inclusive regionalmente (GRANATO, 2014). Além disso, o Consenso de Buenos Aires balizou o início desse período (e o projeto político associado) e expressou vontade política para reformular o Mercosul priorizando também agendas não comerciais (como integração produtiva, participação social, assimetrias interestatais). Em função disso, órgãos foram criados com pertinência às novas prioridades (GRANATO, 2014).

Após novas reconfigurações políticas, especialmente a partir de 2016, o "Mercosul do século XXI" nomeia o projeto em prol do retorno à liberalização comercial, de negociações para ampliação do comércio, e da perda de importância das agendas política e social (FORO CONSULTIVO ECONÔMICO-SOCIAL [FCES], 2019; MELLO; CORRÊA, 2019). Nesse contexto, reunido em julho de 2017, o CMC extinguiu o ARGM por considerar que perdeu adequação às necessidades concretas da etapa vigente, como exposto no preâmbulo da nova decisão. Em sete anos, o que era "a cara” do Mercosul virou órgão inadequado.

Apesar da relevância e reviravolta acima, o órgão não recebeu a atenção acadêmica equivalente. Outros(as) autores(as), em geral, trouxeram considerações secundárias sobre o ARGM, isto é, à margem do problema de pesquisa que propuseram investigar, salvo Bianco (2015). Este artigo, então, visa ocupar o espaço na pesquisa sobre o "novo Mercosul” e compreender as atividades externas do ARGM a partir do processo político em torno dos dois projetos políticos regionais vigentes ao longo da existência do órgão. Assim, interessa apontar as adequações entre as prioridades dos projetos e as atividades externas do órgão, sua criação e extinção. Para isso, uma indagação guia este artigo: como se desenvolveram as atividades do Alto Representante-Geral do Mercosul na dimensão externa e no contexto do "novo Mercosul"? 
Tal indagação e objetivos refletem a compreensão de que projetos de construção social de região existem em convivência em maior ou menor intensidade, tensão, disputa, contradição, rupturas e continuidades, por consequência, sendo politicamente contestados (PERROTTA; PORCELLI, 2016). Desta forma, destacam-se os projetos do "novo Mercosul" e do "Mercosul do século XXI” no período analisado, e não posições particulares de designados ao ARGM ou EstadosPartes. Tal compreensão representa o esforço para ir além da bastante difundida superestimação da União Europeia (UE) como exemplo replicável independentemente de especificidades quaisquer (BRICEÑO-RUIZ, 2018), especialmente, em quesitos institucionais.

Ademais, este artigo foi elaborado a partir de entrevistas, pesquisas bibliográfica e documental. A pesquisa bibliográfica incluiu a revisão crítica e consolidadora do material secundário e esparso sobre o ARGM, sem perder de vista linhas gerais que ultrapassam o intervalo 2010-2017. Os achados da pesquisa documental são dados empíricos para confrontação com o conhecimento crítico da pesquisa bibliográfica e têm origem em documentos institucionais do Mercosul ${ }^{3}$, sobretudo, e em textos jornalísticos. Entrevistas com informantes-chave4 dão acesso a informações não registradas noutras fontes e a perspectivas de quem manteve proximidade ao ARGM. Esse acesso importa ainda mais quando "quase secretamente, há um processo de reforma institucional em curso no Mercosul” (VENTURA; ONUKI; MEDEIROS, 2012, p. 93), transparência limitada e documentos reservados.

Nessas condições, a seção seguinte liga o surgimento do órgão e suas atribuições ao projeto político regional do "novo Mercosul”. Continuando, a análise das atividades desenvolvidas por cada um dos altos representantes-gerais discorre sobre a dimensão política e não a via canônica de negociar com terceiros rumo ao livre comércio como guia das atribuições do ARGM nas relações externas, ao concebê-las de forma abrangente. Em sequência, a extinção do órgão é compreendida na transição entre projetos políticos. No remate, retomar as argumentações anteriores permite sugerir uma direção mais saliente das atividades do ARGM na dimensão externa e caracterizar seu vínculo aos projetos.

\section{CRIAÇÃO E ATRIBUIÇÕES CONFERIDAS AO ARGM}

Balizando o início do "novo Mercosul”, o Consenso de Buenos Aires é um documento bilateral argentino-brasileiro de 2003 em reação às reformas neoliberais na década de 1990 baseadas no Consenso de Washington; no Mercosul, em poucos meses, originou o Programa de Trabalho 20042006 (BIZZOZERO, 2013; DESIDERÁ, 2017; PERROTTA; PORCELLI, 2016; RAMOS, 2015). Esse

\footnotetext{
${ }_{3}$ Salvo se apontado diferente, atas, normativas, informes e relatórios do Mercosul foram acessados no acervo oficial disponibilizado no endereço eletrônico https://documentos.mercosur.int/.

4 Foram entrevistados, em particular, os pesquisadores do Mercosul Lincoln Bizzozero, Marcus M. de Salles (trabalhou na SM de 2015 a 2020) e Rafael N. Reis (chefiou o gabinete do ARGM Doutor Rosinha).
} 
projeto promoveu "a afirmação da ideia da região como ator, a ampliação da agenda da integração para incluir os problemas de desenvolvimento e as políticas sociais” (CLEMENTE, 2017, p. 1, tradução livre).

Houve a intenção de tornar mais visível as relações externas mercosulinas, após a crise do Mercosul e a descoordenação na virada do século (CABALLERO, 2011). A ampliação da agenda regional tornou prioridade temas das dimensões social, política, participativa e distributiva (DESIDERÁ, 2017). O projeto político regional então vigente bancou a adição, como prioridades, de temas em companhia à dimensão comercial, como também se embasou na política como princípio regulador da vida social, inclusive regionalmente (GRANATO, 2014).

Foi o período de crescimento institucional mais intenso, devido às criações sucessivas e incrementais de órgãos em estrita relação com as políticas sociais domésticas e a regional (MIRZA; NASCONE, 2013). Tais mudanças institucionais foram também tratadas como desenvolvimento de robustez institucional (LEITE, 2018), particular aperfeiçoamento da capacidade institucional (LIMA, 2016), e uma "aluvião institucional” de crescimento disperso e em ocasiões desordenadas (GIACOBONE, 2016, p. 8). Para explicar a relação entre os temas priorizados e a criação de órgãos, Mirza e Nascone (2013) comentaram que eram necessárias estruturas que perseguissem as novas prioridades, pois estas ocasionaram uma acumulação conceitual; isto é, foi requerida uma acumulação institucional em vista dos órgãos existentes (especialmente os decisórios) estruturados para a dimensão comercial.

Nesse contexto e propósito do "novo Mercosul”, está a criação do ARGM (DESIDERÁ, 2017; ESPINO, 2016; RAMOS, 2015). Pelo ponto de vista histórico de Granato (2014), o ARGM constituiu um órgão encarregado de continuar a reformulação iniciada em 2003. Similarmente, o ARGM, o plano de ação para a conformação de um Estatuto da Cidadania do Mercosul (PA-ECM), o Plano Estratégico de Ação Social (PEAS) e o Programa de Consolidação da União Aduaneira (PCUA) representam decisões que reafirmaram em 2010 a definição das prioridades regionais e da orientação para o futuro próximo do Mercosul nas dimensões política, cidadã, social e econômica, respectivamente (BIZZOZERO; RODRÍGUEZ, 2015).

Bizzozero e Rodríguez (2015) trataram do entrelaçamento do ARGM nas dimensões temáticas ao destacar que cabia a ele implementar o PA-ECM e o PEAS. Nessa ideia de entrelaçamento, a criação do ARGM com responsabilidade sobre a Unidade de Apoio à Participação Social (UPS)5 o implica na dimensão participativa (ESPINO, 2016). Já na dimensão política, o ARGM foi implicado por expressar fortalecimento institucional no aspecto da cultura democrática (GRANATO, 2014) e por ser um dos múltiplos atores de um campo político policêntrico próprio do Mercosul (SCHNEIDER, 2015).

\footnotetext{
5 A UPS foi criada em 2010 para ser canal institucional com a sociedade, inclusive de apoio, coordenação, registro e financiamento à participação social (GRANATO, 2014).
} 
Aprovado em 2010, o PCUA definiu, em seu artigo 58, que “a ação externa do Mercosul será desenvolvida mediante a negociação de mecanismos de vinculação política, comercial ou de cooperação com terceiros países ou grupo de países”. Com isso, Bizzozero e Rodríguez (2015) associaram o ARGM às vinculações políticas nas relações externas do Mercosul. Logo, dimensões se entrelaçavam no ARGM revelando seu cariz multidimensional, embora fosse proeminentemente político.

Antecedendo a criação do ARGM pelo CMC, em outubro de 2010, o governo brasileiro propôs a criação de quatro cargos ao Grupo do Mercado Comum (GMC), conforme a ata: um alto representante-geral mais três específicos (saúde, cultura e cooperação para o desenvolvimento). Contudo, pela ata, a "Delegação do Paraguai recordou que devem ser levados em conta os temas originários da agenda do Mercosul, sobretudo os comerciais e agrícolas”. Em dezembro, a Decisão CMC n. 63 de 2010 criou somente o ARGM.

O preâmbulo da decisão justificou a criação pela "necessidade de adaptar a estrutura institucional do Mercosul às mudanças ocorridas" e de "uma estrutura que permita melhor projeção do Mercosul”. E remeteu às normativas que estabeleceram a reestruturação da Secretaria do Mercosul (SM) e o ajuste da Comissão de Representantes Permanentes do Mercosul (CRPM) a ela. Pela Decisão CMC n. 56 de 2008, as diretrizes para a reestruturação da SM possibilitaram a SM a assumir funções conferidas à CRPM. Paralelamente, a Decisão CMC n. 32 de 2008 estendeu para o fim de 2009 o mandato do último presidente da CRPM, antes da eliminação tácita do cargo.

Apresentação de propostas, assistência à Presidência Pro Tempore (PPT) e, ao CMC, participação das reuniões de órgãos do Mercosul e representação externa foram funções sugeridas nas diretrizes para serem desenvolvidas pela Secretaria. Contudo, essas funções acabaram sendo conferidas ao ARGM em 2010, o que explica a recorrente ligação com a CRPM (CABALLERO, 2011, 2013; PEIXOTO; PERROTTA, 2018; PERROTTA; PORCELLI, 2016). Comparativamente, o ARGM assumiu maiores competências e um alegado novo cariz em relação ao presidente da CRPM (CABALLERO, 2011, 2013).

Em análise da estrutura institucional, Ribeiro (2012) inseriu o ARGM no "poder executivo" do Mercosul. Os órgãos desse "poder executivo" foram classificados em níveis, a partir de critérios especificamente voltados ao processo de produção de normas. Os critérios conformaram a estrutura institucional mercosulina em formato piramidal. Tal pirâmide evidencia a distância entre poder decisório e canais de demanda da sociedade e a subordinação de órgãos dos níveis basilares aos de cima. O ARGM, então, foi situado no meio da pirâmide ao ser classificado como um dos órgãos técnicos e consultivos de primeiro plano. Ribeiro (2012) assim o classificou, porque o cargo é ocupado por autoridades designadas pelos Estados-Partes para cumprimento de mandato e uma de suas atribuições é apresentar propostas sobre diversos temas.

Apesar da distância à abertura à sociedade civil apontada por Ribeiro (2012), como o ARGM está no meio da pirâmide, tinha a capacidade de coordenar os órgãos que têm a abertura e de 
apresentar ao topo decisório-executor da pirâmide as propostas temáticas advindas de demandas sociais para impulsionar o experimento regional, tratadas por Peixoto e Perrotta (2018). Tal análise apoia a associação entre o ARGM e a dimensão política e sua capacidade institucional para exercer a articulação política intra-Mercosul, mesmo para a agenda externa.

Diferentemente do presidente da CRPM, esteve sob responsabilidade do ARGM, além da UPS, um gabinete administrativo com funcionários concursados permanentes (ÁLVAREZ; PEYRANI, 2011) - conforme Figura 1. Pela norma criadora, o ARGM contava com assessores (diplomatas), o gabinete, um chefe de gabinete e mandato (prorrogável uma única vez e com rotação de nacionalidade). Além disso, dispôs de acordo de sede para o funcionamento no mesmo edifíciosede da SM, em Montevidéu, e de orçamento próprio, cujo rateio reconhecia assimetrias interestatais.

Figura 1: Organograma do ARGM

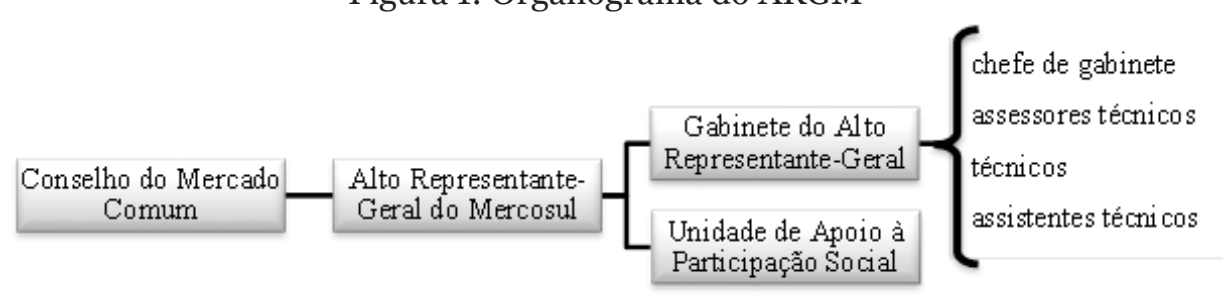

Fonte: Pessoa (2020, p. 78).

Tais características colocam o ARGM como um dos poucos órgãos do Mercosul que dispuseram de todo esse aparato institucional. Ademais, a SM compartilhou a sede com o ARGM e devia prestar apoio a ele em suas atribuições, incluindo a elaboração de estudos, conforme previstos na criação dele. Assim, concedia alguma função política à SM (BARTESAGHI; PEREIRA, 2016) ao apoiar o ARGM, pois a atuação essencialmente política orientava as atenções do pessoal técnico da SM nas solicitações de estudos.

O ARGM foi um cargo unificado, em vez da configuração quadripartite comum no Mercosul (REQUIÃO, 2011). Nessa situação, "um coordenador [era] indicado pelos quatro países, legitimado pela delegação comum e, portanto, apto a tomar providências de maneira mais expedita, embora necessite de referendo quadripartite posterior" (REQUIÃO, 2011). Mas, por vezes, eram postos limites a essa atuação mais expedita, principalmente na dimensão externa. Para o ARGM exercer sua função de representação externa perante terceiros, precisava de mandato expresso do CMC.

O Alto Representante tinha uma função de representar internacionalmente o Mercosul. Então, ele, para fazer isso, precisava conversar com todos os países. Precisava fazer essas consultas internas antes. Ele não podia manifestar o interesse do Mercosul em negociar. Ele tinha de dizer: eu vou receber essa demanda de vocês. Estar na posição de Alto Representante-Geral e ficar tomando nota e encaminhar pedido desmerece a função, né? Por isso que ele trabalhava pouco em relacionamento externo e foi se metendo na agenda que tinha mais capacidade de atuação. Ele tinha uma agenda de relacionamento externo bastante presente, mas 
não gostava muito porque não tinha carta branca para trabalhar (SALLES, comunicação pessoal, 25 de setembro de 2020).

Os assuntos externos se mostraram sensíveis a tensões dentro do "novo Mercosul", o que é reforçado ao saber que "houve várias divergências com as Chancelarias sobre o papel que deveria desempenhar o ARGM” (REIS, comunicação pessoal, 27 de maio de 2019). Apesar de tensões, divergências, pairou no "novo Mercosul" a estima pelo regional contemplando o conjunto de perspectivas nacionais (PEIXOTO; PERROTTA, 2018) em um órgão permanente e unificado em "uma personalidade que seja a cara visível do Mercosul" (ARSLANIAN, 2012, p. 90). Assim, despontou a orientação política, mas cabendo aprofundar na seção seguinte a análise das atividades externas do ARGM ao exercer as atribuições de representação externa, participação em eventos e seminários, divulgação e promoção cultural, comercial e de investimentos.

\section{ATIVIDADES DO ARGM NAS RELAÇÕES EXTERNAS DO MERCOSUL}

Os Estados-Partes conferiram a condução das ações externas do Mercosul aos três órgãos decisórios (CARNEIRO, 2007) e ao ARGM coube outras funções conexas às relações externas do Mercosul. Nisso, o ARGM foi posicionado quanto a ações externas ante os mecanismos de vinculação política (BIZZOZERO; RODRÍGUEZ, 2015). Mas também, o ARGM foi visto como prática política da estratégia de desenvolvimento do Brasil via cooperação sul-sul na estrutura institucional do Mercosul (DESIDERÁ, 2015).

Altos representantes-gerais repercutiram o discurso sobre o Mercosul ampliado, que era majoritário nos governos argentino, brasileiro e venezuelano (GIACALONE, 2017). A proposta de Mercosul ampliado mira novos membros e a consideração da vizinhança política para a aproximação com os países sul-americanos que ainda não são Estados-Partes do Mercosul (GIACALONE, 2017). Portanto, o ARGM avançou para o alcance sul-americano pelo Mercosul (BIZZOZERO, 2013) ao ser capaz de impulsionar assuntos abrangentes aos Estados associados.

Por outro lado, o cotidiano das atribuições do órgão esteve ocupado mais pela impulsão do processo regional e menos pela representação externa (BIANCO, 2015). Numa comparação com "a função de relações externas”, “os trabalhos desenvolvidos relativos à dinâmica de articulação institucional entre os órgãos do Mercosul para a implementação do Estatuto da Cidadania, missões de observação eleitoral, integração produtiva e promoção comercial tiveram um peso maior” (REIS, comunicação pessoal, 27 de maio de 2019). Em suma, o ARGM "era muito mais ativo na agenda interna" (SALLES, comunicação pessoal, 25 de setembro de 2020).

Contudo, avaliando as atividades do ARGM na dimensão externa, foram "duas facetas: cumpriu um papel no espaço regional [da América do Sul] e praticamente nenhum nas negociações restantes, o que limitou a figura de alto representante" (BIZZOZERO, comunicação pessoal, 28 de 
setembro de 2020, tradução livre). Sem negar limitações, esta concepção abrangente contesta a equiparação da dimensão externa às negociações de livre comércio e a concepção de representação externa exclusivamente aos moldes da UE defendidos por Bianco (2015), o que suscita diminuir a relevância da agenda externa empreendida.

Para corroborar a concepção abrangente, cabe recorrer aos achados da pesquisa documental. Parte do conjunto documental está relacionada ao CMC, ao qual o ARGM foi vinculado e devia reportar-se em relatórios semestrais e programas de trabalho anuais conforme a normativa criadora (o que foi sintetizado na Figura 2). Abarcando essa parte dos documentos, bem como aqueles referentes ao GMC e outros, a análise aqui acompanha cronologicamente as atividades de cada um dos três homens de nacionalidade brasileira designados ao cargo, conforme Quadro 1.

Figura 2 - O ARGM nas reuniões do CMC

\begin{tabular}{|c|c|}
\hline (dex. 20 & lecisão $\mathrm{CMC}$ n. 6 \\
\hline $\begin{array}{l}\text { CLI Reunião Ordinária } \\
\text { (jun. 2011) }\end{array}$ & $\begin{array}{l}\text { Dec. } 1 / 2011 \text { - Designaçào de Samuel P. Guimarães } \\
\text { Sem relatório escrito, conforme a ata. }\end{array}$ \\
\hline $\begin{array}{l}\text { LII Reuniào Ordinária } \\
\text { (dez. 2011) }\end{array}$ & $\begin{array}{l}\text { Documento Informativo (DI) n. } 13 \text { de } 2011 \text {-RESERVADO. } \\
\text { Relatório semestral do ARGM }\end{array}$ \\
\hline $\begin{array}{l}\text { X Reunião Extraordinária } \\
\text { (dez. 2011) } \\
\end{array}$ & Sem documentos. \\
\hline $\begin{array}{l}\text { XIIII Reuniâo Ordinária } \\
\text { (jun. 2012) }\end{array}$ & DI 2/2012 - RESERVADO. Relatório semestral do ARGM \\
\hline $\begin{array}{r}\text { Reuniăo } \\
\text { (ju }\end{array}$ & Dec. 29/2012 - Designação de Ivan Ramalho \\
\hline $\begin{array}{r}\text { XLIV Reun } \\
\text { (de }\end{array}$ & $\begin{array}{l}\text { DI } 7 / 2012 \text { - Relatório semestral do ARGM } \\
\text { • progr ama de trabalho para } 2013 \\
\text { Dec. } 33 / 2012 \text { - Contribui çes da Venezuela ao orçamento } \\
\text { Dec. } 64 / 2012 \text { - Participação na Aliança do Pacifico como observador }\end{array}$ \\
\hline $\begin{array}{r}\text { XLV Reuni } \\
\text { (ju }\end{array}$ & $\begin{array}{l}\text { DI } 2 / 2013 \text { - Relatório semestral do ARGM } \\
\text { Dec. } 15 / 2013 \text { - Participação no Sistema da Integração Centro- } \\
\text { Americana como observador } \\
\text { Dec. } 16 / 013 \text { - Acordo de sede }\end{array}$ \\
\hline $\begin{array}{l}\text { I Rean } \\
\text { (ju }\end{array}$ & $\begin{array}{l}\text { DI } 2 / 2014 \text { - RESERVADO. Relatório semestral do ARGM } \\
\text { • programa de trabalho para } 2014 \text { (conforme a ata) } \\
\text { Dec. } 8 / 2014 \text { - Designação de Ivan Ramalho }\end{array}$ \\
\hline $\begin{array}{r}\text { XLVII Rean } \\
\text { (dez }\end{array}$ & $\begin{array}{l}\text { DI 13/2014 - Relatório semestral do ARGM } \\
\text { - lista de atividades + pró-memórias das visitas oficiais da CEEA e } \\
\text { do TPI } \\
\text { Dec. } 19 / 2019 \text { - Participação do Mercosul como observador em } \\
\text { processos regionais de integração e organismos internacionais }\end{array}$ \\
\hline $\begin{array}{l}\text { XLVIII Reuniâo Or } \\
\text { (jul. 2015) }\end{array}$ & $\begin{array}{l}\text { DI } 2 / 2015 \text { - Relatório semestral do ARGM } \\
\text { • lista de atividades } \\
\text { Dec. } 1 / 2015 \text { - Designação de Doutor Rosinha }\end{array}$ \\
\hline $\begin{array}{l}\text { XLIX Reuniào Ordinária } \\
\text { (dez. 2015) }\end{array}$ & $\begin{array}{l}\text { DI 9/2015 - Relatório semestral do ARGM } \\
\text { • programa de trabalho para } 2016 \text { + lista de atividades } \\
\text { • pró-memória de reunião sobre complementação e articulação } \\
\text { Mercosul-UNASUL } \\
\text { Dec. } 15 / 2015 \text { - Normas gerais p/ funcionários Mercosul (apêndice V) }\end{array}$ \\
\hline $\begin{array}{l}\text { XI Reunião Extraordii } \\
\text { (dex. 2016) } \\
\end{array}$ & Sem documentos. \\
\hline & $\begin{array}{l}\text { Dec. } 6 / 2017 \text { - Derrogação da Dec. } 63 / 2010 \\
\text { Sem relatório, conforme a ata. Cargo estava vago já. }\end{array}$ \\
\hline
\end{tabular}

Fonte: Adaptado de Pessoa (2020, p. 92). 
Quadro 1 - Os três designados ao cargo de Alto Representante-Geral

\begin{tabular}{|c|c|c|c|c|}
\hline Mandato & Pessoa designada & Designação & Início & Fim \\
\hline \multirow{2}{*}{1} & Samuel Pinheiro Guimarães & Dec. $1 / 2011$ & 1 fev. 2011 & 27 jun. 2012 \\
\hline & \multirow{2}{*}{ Ivan Ramalho } & Dec. $29 / 2012$ & 1 ago. 2012 & 31 jan. 2014 \\
\hline \multirow{2}{*}{2} & & Dec. $8 / 2014$ & 1 fev. 2014 & 12 jan. 2015 \\
\hline & Doutor Rosinha & Dec. $1 / 2015$ & 25 fev. 2015 & 31 jan. 2017 \\
\hline
\end{tabular}

Fonte: Pessoa (2020, p. 84).

Samuel Pinheiro Guimarães, primeiro designado ao cargo, apresentou relatórios semestrais escritos somente em dezembro de 2011 e junho de 2012, que foram classificados como "reservados". Entretanto, a Representação Brasileira no Parlamento do Mercosul publicou o último, no qual Guimarães (2012) tratou da expansão geográfica do Mercosul e da negociação conjunta. Ele se posicionou pela expansão gradual com a adesão de Equador, Bolívia, Guiana e Suriname, diante dos compromissos tarifário-comerciais distintos assumidos por Chile, Colômbia e Peru para fora da América do Sul (GUIMARÃES, 2012).

Para o futuro, Guimarães (2012) não descartou a adesão daquele trio ao recomendar ampliar a cooperação econômica e política nas relações do Mercosul com eles. Esses posicionamentos objetivam a construção da América do Sul como bloco do mundo multipolar, a partir do Mercosul como pedra fundamental e, nomeadamente, não da União de Nações Sul-Americanas (UNASUL). O fortalecimento desse novo bloco seria desinteressante para grandes potências nas negociações econômico-comerciais comparando com negociações com Estados individuais. Guimarães (2012) coadunou o objetivo para o mundo multipolar com a promoção regional do desenvolvimento, o que privilegiaria a referida ordem de adesões conforme semelhança de compromissos tarifáriocomerciais.

O conteúdo desse segundo relatório, em geral, já estava presente no informe apresentado pelo ARGM ao GMC em junho de 2011. Para além do reafirmado no segundo relatório, no informe ao GMC, Guimarães argumentou que as atribuições do órgão são essencialmente políticas e programou suas atividades em oito eixos. Um deles foi a expansão geográfica do Mercosul, no qual afirmou ser reduzida a possibilidade de adesão ao Mercosul de um Estado exterior à América do Sul. Outro eixo foi transformar a imagem do Mercosul, pois, dentre razões apontadas, a imagem negativa seria fruto de veiculação midiática sobre um suposto maior proveito econômico de tratados de livre comércio com economias desenvolvidas, em comparação a benefícios decorrentes do Mercosul e de suas ações externas em conjunto.

O segundo relatório foi apresentado ao CMC reunido em junho de 2012 com sua renúncia. Sendo cargo político, Guimarães atribuiu sua renúncia exclusivamente à falta de apoio político pelos governos para seus projetos, enquanto que veículos jornalísticos especularam outras razões da renúncia (CARTACAPITAL, 2012; G1, 2012). Como atas do CMC e GMC só registraram positivamente Guimarães, a falta de apoio pode aludir aos limites da delegação pelos Estados-Partes. 
Pelas referidas especulações, ele teria renunciado por questionar o modo da adesão da Venezuela e da suspensão do Paraguai, por discordar quais países sul-americanos seriam prioritários na aproximação com o Mercosul, por divergir com o Itamaraty, com seu titular Antonio Patriota e/ou com a presidenta brasileira Dilma Rousseff, ou ainda por causa duma distinção em termos de ideologia versus pragmatismo (BONAVINO, 2012; FIGUEIREDO, 2012; MONTEIRO; PALACIOS, 2012).

Ivan Ramalho, segundo designado ao órgão, se disponibilizou para missões ao Equador e Bolívia seguindo o mandato determinado pelo CMC, conforme ata da reunião do GMC em outubro de 2012. Já no relatório semestral ao CMC reunido em dezembro de 2012, Ramalho especificou que chefiou as missões à Bolívia, Guiana e Suriname e participou de missão ao Equador. Todas elas sob o objetivo de aproximar esses países ao Mercosul. Ramalho também estabeleceu um programa de trabalho para o ano de 2013. Nele, projetou realizar missões comerciais conjuntas (aos quatro países referidos e a outros) e listou organizações internacionais ao estreitamento de relações com o Mercosul.

Ainda em dezembro, pela Decisão CMC n. 64 de 2012, o CMC decidiu solicitar a participação do Mercosul na Aliança do Pacífico (AP) como observador. Essa participação seria exercida pelo ARGM em representação do Mercosul. O preâmbulo desta decisão a explicou pela "importância atribuída pelos Estados-Partes do Mercosul a iniciativas comerciais na região”. Tal decisão correspondeu a uma tentativa de dissuadir uma propensão unilateral uruguaia (BARTESAGHI, 2013). Ainda assim, em maio de 2013, na VII Cúpula da AP em Cáli, o Uruguai demonstrou disposição em se converter em membro pleno da AP (ACTIS, 2014). Ramalho reagiu defendendo que o Mercosul e não o Uruguai sozinho negociasse com a AP (ACTIS, 2014).

No relatório semestral ao CMC de 11 de julho de 2013, Ramalho narrou missões aos mesmos quatro países do relatório anterior. Também esteve presente à VII Cúpula da AP e seu documento resultante, a Declaração de Cáli, registrou a saudação a representante(s) do Mercosul, sem mais que isso.

Em cumprimento ao estipulado no relatório anterior, Ramalho esteve presente na I Cúpula de Chefes e Chefas de Estado e de Governo da Comunidade de Estados Latino-Americanos e Caribenhos (CELAC), em Santiago. Participou ainda da VII Reunião Ministerial da Zona de Paz e Cooperação do Atlântico Sul (ZOPACAS), em Montevidéu, sem que estivesse listada no programa de trabalho. No primeiro semestre de 2013, registrou na lista de atividades dois eventos relativos à ampliação do Mercosul: os seminários “Socialização do processo de adesão da Bolívia ao Mercosul”, na Bolívia, e "Ampliação dos processos de integração regional: ALADI, Mercosul e UE", na Argentina.

Com o Paraguai reintegrado ao Mercosul no CMC reunido em julho de 2013, este aprovou em agosto o acordo de sede para o ARGM. Aprovou também a solicitação ao Sistema da Integração Centro-Americana (SICA) para dele o Mercosul participar na condição de observador e representado 
pelo ARGM, conforme Decisão CMC n. 15 de 2013. Esta decisão repetiu aquela referente à AP, mas sem evocar destacadamente o aspecto comercial no preâmbulo da decisão. Porém, não foram encontrados documentos da AP ou da SICA anuindo, ou considerando, tal tipo de participação do Mercosul.

As atividades do segundo semestre de 2013 e primeiro de 2014 foram tratadas no relatório classificado como "reservado" e apresentado à reunião do CMC de julho de 2014. Já em outubro de 2014, o GMC aprovou o convite da Organização das Nações Unidas (ONU) para Ramalho participar da II Conferência das Nações Unidas sobre Países em Desenvolvimento sem Litoral, em Viena, em novembro de 2014. Embora possa envolver discussões vinculadas a outro marco legal internacional (o Tratado da Bacia do Prata, de 1969), Ramalho sugeriu, em seu relatório ao GMC de novembro de 2014, o tratamento pelo Mercosul das pautas de alfândegas, facilitação do trânsito e acesso de produtos de países mediterrâneos (Paraguai e Bolívia), financiamento de infraestrutura.

No relatório semestral ao CMC, de 15 de dezembro de 2014, cabe destacar pró-memórias anexados por Ramalho, que versaram sobre visitas recebidas no segundo semestre de 2014. Ramalho recebeu e manifestou que encaminharia as demandas para os órgãos decisórios. Uma visita foi a do presidente do Tribunal Penal Internacional (TPI), em julho de 2014, e a outra se referiu às relações entre o Mercosul e a Comunidade Econômica Eurasiática (CEEA), remissíveis ao objetivo para o mundo multipolar de Guimarães.

Em reunião com o ARGM em julho de 2014, autoridades da CEEA demonstraram interesse pela estrutura e funcionamento do Mercosul, após exporem semelhanças entre as duas organizações. O interesse demonstrado e a sugestão de comparação de experiências e troca de informações insinuam um princípio de difusão institucional entre o Mercosul e a CEEA, ainda mais que um tratado de 2014 promovia nesse momento a substituição da CEEA pela União Econômica Eurasiática (UEE) (DIAS, 2015). Fora isso, sondaram a perspectiva de concluir um memorando entre as duas partes - assinado depois, em 2018.

Posteriormente, a Decisão CMC n. 19 de 2014 possibilitou que o GMC instruísse o ARGM a representar o Mercosul em experimentos de regionalismo e organismos internacionais. Assim, ocorreu algo como uma regularização da medida tomada pelo GMC ao aprovar a participação do ARGM na conferência sobre países mediterrâneos (sem litoral) - sem registros de quaisquer questionamentos sobre essa atividade, a da ZOPACAS ou outra. Além disso, veio a generalizar as decisões sobre AP e SICA, pois seu preâmbulo reforçou a ideia presente nelas: acrescentar a visão do Mercosul tornando conhecidas suas experiências em instituições internacionais de seu interesse.

Florisvaldo Fier (mais conhecido como Doutor Rosinha), terceiro designado ao órgão, logo recebeu mandato do GMC para representar o Mercosul em nova reunião relativa à conferência da ONU. E, dentre as atividades narradas no relatório semestral ao CMC de julho de 2015, Rosinha coordenou ações para o trabalho conjunto com a UPS e o Instituto de Políticas Públicas em Direitos Humanos (IPPDH), resultando no mandato conferido ao IPPDH para atuar na convergência entre 
Mercosul e UNASUL. Coordenou ainda o trabalho conjunto com o Fórum Especializado Migratório (FEM) e o Subgrupo de Trabalho n. 10 "Assuntos Trabalhistas, Emprego e Seguridade Social” (SGT10) visando aos contatos com a Organização Internacional para as Migrações (OIM), diante do Memorando de Cooperação entre o Mercosul e a OIM de 2014.

Após essas experiências, Rosinha recebeu mandato para representar o Mercosul e participou da II Reunião sobre Convergência de Mecanismos de Integração Sub-Regionais, organizada pela Secretaria-Geral da UNASUL (SG-UNASUL) em agosto de 2015. Em relatório ao GMC de novembro de 2015, Rosinha tratou da duplicidade e aproximação nessa agenda de complementação e articulação com a UNASUL. Ele propôs aperfeiçoar as instituições aproveitando aquelas já consolidadas. Com isso, privilegiou o Mercosul ao argumentar que não há institucionalidade consolidada na UNASUL e os países sul-americanos são Estados-Partes ou associados do Mercosul.

Noutro ponto, Rosinha posicionou a UNASUL como vitrine para êxitos dos demais regionalismos. Novamente privilegiou o Mercosul ao propor ampliar a cobertura/adesão às experiências exitosas, nomeadamente estendendo para o restante dos Estados associados os acordos firmados no seio do Mercosul, tais como os das áreas de educação e de cooperação jurídica internacional. Ao fim do relatório, Rosinha cogitou várias propostas evocando uma "agenda imediata possível”, como a identificação de objetivos do PA-ECM e do PEAS de interesse dos Estados associados e até a convergência entre o Parlamento do Mercosul e o Parlamento Sul-Americano.

$\mathrm{Na}$ lista de eventos anexa ao relatório semestral ao CMC de dezembro de 2015, alguns envolveram a China, incluindo uma viagem oficial ao país. Noutro evento de destaque, o ARGM concedeu audiência a representantes da UE sobre as negociações interregionais de livre comércio (CHAMORRO, 2015). Sem autorização para negociar externamente, o tom foi político. E, também apresentado ao CMC do fim de 2015, o programa de trabalho para 2016 trouxe novidades perante o de 2013, refletindo, principalmente, o crescimento da UNASUL nas atividades do ARGM.

Ao GMC, reunido em maio de 2016, Rosinha apresentou um relatório específico sobre sua participação na IV Reunião sobre Convergência de Mecanismos de Integração Sub-Regionais, ocorrida em março de 2016. Rosinha comentou no relatório cada um dos temas sugeridos pela SGUNASUL, com destaque aqui a dois deles. A intenção da SG-UNASUL para um plano integral de cidadania sul-americana centrado na migração foi caracterizada por Rosinha como exemplo certo de projeto evitável. Isso porque resultará em duplicação de esforços com Estatuto Migratório Andino e com o processo de discussão e elaboração de um acordo único migratório desenrolado no Mercosul. Este processo no Mercosul busca ampliar, segundo Rosinha, o Acordo de Residência do Mercosul existente em termos de direitos e de Estados signatários com a participação dos Estados associados.

Em avaliação diametralmente oposta, Rosinha elogiou os avanços do trabalho articulado entre Mercosul e UNASUL no tema da saúde. Ele afirmou que as reuniões de ambos eram realizadas simultaneamente, para as quais o então Instituto Sul-Americano de Governo em Saúde funcionava 
como braço técnico (ausente no Mercosul) à convergência sul-americana em saúde. Além disso, tais discussões convergentes já previam novas pautas.

Em junho de 2016, o GMC aprovou o perfil técnico do projeto "Promoção do direito à livre mobilidade no Mercosul" a ser executado e financiado pela OIM e pelo ARGM e em linha ao memorando Mercosul-OIM. Para isso, Rosinha contatava o Diretor Regional da OIM para América do Sul e coordenava o FEM e o SGT-10, consoante formulário anexo à ata do GMC. O projeto objetivou investigar efetivação, alcances e impactos do Acordo sobre Residência para Nacionais dos Estados-Partes do Mercosul, Bolívia e Chile. Firmado em 2002, este acordo entrou em vigor em 2009 e recebeu a adesão da maioria dos Estados associados. A despeito da extinção do ARGM em 2017, o projeto foi concluído e produziu dois estudos, conforme registrou o relatório da CRPM ao CMC reunido em julho de 2019.

Após junho de 2016, CMC e GMC se reuniram só uma vez e de forma extraordinária - numa paralisia da rotina de reuniões similar à de 2013, após suspensão do Paraguai e entrada da Venezuela em 2012. Desta vez, o mandato de Dilma Rousseff foi impedido e a Venezuela, suspensa. O mandato de Rosinha acabou em janeiro de 2017 e, em julho, o CMC extinguiu o ARGM. Diante desse contexto político-institucional de 2016, não houve apresentação de relatórios ao CMC de 2016 ou 2017, nem ao GMC depois de junho.

\section{EXTINÇÃO DO ARGM NA TRANSIÇÃO ENTRE PROJETOS POLÍTICOS}

As atividades do ARGM estão registradas até junho de 2016, ainda que tenha orçamento para o exercício de 2017 aprovado pelo GMC reunido em caráter extraordinário e na única vez do segundo semestre de 2016, já sem a presença da Venezuela (suspensa). Também extraordinariamente em dezembro de 2016, o CMC reunido na única vez daquele ano agradeceu a gestão de Rosinha no ARGM, cujo mandato findaria já em 31 de janeiro de 2017. Sem mais, não houve designação de nacional do Paraguai ao órgão, como previa o princípio da rotação de nacionalidades na criação.

Discussões sobre a designação seguiram até que, em abril de 2017, o GMC instruiu o Grupo de Análise Institucional do Mercosul a apresentar uma proposta de normativa a fim da supressão do órgão. Essa proposta foi apresentada ao GMC reunido em junho de 2017 e, naquele mês, foi aprovada a extinção pela Decisão CMC n. 6 de 2017. Com o orçamento para 2017 aprovado, a distribuição dos recursos foi sendo discutida até 2019.

O preâmbulo da normativa que estabeleceu o fim do órgão traz três considerações para a decisão de extinguir: o CMC não mais considerar o órgão pertinente; o órgão ser adequado às necessidades da etapa anterior e não da etapa presente do processo regional; e seu funcionamento não contribuir para a racionalização dos recursos financeiros, dos recursos humanos e da estrutura institucional. Segundo o FCES (2019), após a confusão e paralisia interna no Mercosul e os novos 
governos na Argentina (Mauricio Macri) e Brasil (Michel Temer) em 2016, um novo cenário se abriu em 2017, dando início ao "Mercosul do século XXI”. Essa expressão cunhada pelos novos presidentes (FCES, 2019) pode denominar a "etapa presente" antes referida.

O “Mercosul do século XXI” é compatível aos projetos políticos nacionais em ascensão desde 2012-2013 (incompatíveis com o "novo Mercosul”) e que tencionavam o retorno do "ciclo político neoconservador-neoliberal” (PERROTTA; PORCELLI, 2016, p. 77). O propósito de racionalização dos recursos financeiros e humanos coaduna com a tese de uma "reorientação pautada no discurso de otimização comercial, gestão efetiva de recursos e defesa da democracia” (LIRA, 2019, p. 59). Porém, o órgão não possuía o maior orçamento.

A racionalização da estrutura institucional coincide com as visões de estancamento do Mercosul, de êxito na AP e de necessidade de aproximar a estrutura institucional do Mercosul à da AP (CLEMENTE, 2017; MOLINA, 2019). Igualmente, o fim das cúpulas sociais, a vacância na coordenação da UPS em 2017, as propostas de conversão do Mercosul em zona de livre comércio, e a flexibilização das instituições do Mercosul pelo bilateralismo conformam um processo de redução a uma institucionalidade mínima no Mercosul desde 2015 (CLEMENTE, 2017). A extinção do ARGM foi o caso mais notável (CLEMENTE, 2017).

A impertinência do órgão mencionada no preâmbulo pode ser compreendida em motivações expostas pelo chanceler paraguaio Eladio Loizaga, já que a extinção foi proposta pelo Paraguai. Loizaga alegou que cabia ao CMC a representação política do Mercosul, o ARGM constituía sobreposição de funções e certos posicionamentos do último designado geraram controvérsia interna (ABC COLOR, 14 de março de 2017, 24 de julho de 2017; EFE, 2017; INFORME INDUSTRIAL, 2017; LA DIARIA, 2017). Por outro lado, Rosinha foi caracterizado como grande apoiador do Paraguai (ABC COLOR, 21 de dezembro de 2016).

Ademais, Rosinha opinou contra a suspensão da Venezuela em resposta ao então candidato presidencial argentino Mauricio Macri (DIARIO VICTORIA, 2015; EFE, 2015). Mais tarde, ecoou a possibilidade de suspensão do Brasil pela destituição de Dilma Rousseff (ABC COLOR, 27 de março de 2016; LA DIARIA, 2015; NUEVO DIARIO, 2016). Pelos acontecimentos de 2016, a situação foi bem distinta daquela entre Ramalho e o Uruguai.

A suspensão da Venezuela, onde começou a se deteriorar o clima interno, depois com o impeachment da Dilma. Ali, a base dele [Rosinha] vai por água abaixo. Durante a suspensão da Venezuela, ele começa a se posicionar contra evocar a cláusula democrática nesse caso e a se queimar com o Paraguai e com a Argentina. Depois ele vai tentar contornar ao longo de 2016 (SALLES, comunicação pessoal, 25 de setembro de 2020).

A dimensão política própria ao ARGM para a atribuição de coordenação/articulação se mostrou como uma politização indesejada pelo "Mercosul do século XXI". Também, o processo de deterioração relatado corrobora que havia projetos incompatíveis ascendendo e coexistindo com o “novo Mercosul”, marcando uma transição política, à qual o ARGM sucumbiu. 


\section{CONSIDERAÇÕES FINAIS}

Cabe retomar, à guisa de remate, a indagação apontada inicialmente: como se desenvolveram as atividades do Alto Representante-Geral do Mercosul na dimensão externa e no contexto do "novo Mercosul”? Considerando-se que o processo político no Mercosul alcançou uma transição condizente à reconfiguração política sul-americana de 2016, o argumento aqui propugnado é a criação e as atividades externas do ARGM terem se desenvolvido voltadas à América do Sul e em adequação ao "novo Mercosul" até perder tal condição com a vigência de outro projeto político regional, o "Mercosul do século XXI".

Em conformidade ao "novo Mercosul", o ARGM impulsionou temas tornados prioritários desde 2003 e, com a interface para o exterior, atuou para melhorar a projeção do Mercosul em uma direção mais saliente. Mercosul ampliado, eixo da expansão geográfica, alcance sul-americano e formação de polo da multipolaridade compreendem de formas variadas que as atividades se dirigiram destacadamente à América do Sul. Tal direção assinalava a atuação política do órgão, presente mesmo em temas comerciais, de direitos humanos, migração, saúde, em negociações comerciais e projetos de cooperação.

Os três altos representantes-gerais colocaram o Mercosul em posição centrípeta dentro da convergência sul-americana, como nas edições da Reunião sobre Convergência de Mecanismos de Integração Sub-Regionais, no projeto com a OIM e na pauta dos países mediterrâneos. Eles incitaram ao aproveitamento das experiências do Mercosul e almejaram iniciativas que abarcassem Estados associados. Foram "a cara” dele e buscavam divulgá-lo, projetá-lo e melhorar sua imagem. Adicionalmente, isso permite uma compreensão ampla das atividades na dimensão externa para além de negociações externas para o livre comércio, ou de canais formalmente institucionalizados, ou ainda de aparatos decisório-coercitivos.

Divergências sobre o papel a ser desempenhado pelo "novo" órgão se acentuaram na ascensão dos projetos nacionais incompatíveis com o "novo Mercosul". Com a transição e acirramento da disputa entre projetos em 2016, a atuação política do ARGM colidia com os intuitos do "Mercosul do século XXI" em favor da otimização institucional e desprestígio das dimensões social e política. Finalmente, nas relações externas, as negociações liberalizantes substituíram, como prioridade, o intento da região como ator (político) no mundo, endereçando a inadequação do ARGM e sua extinção.

Compreensões apresentadas neste artigo, embora suportadas por amplo contexto, não cobrem todos os aspectos do ARGM, nem confere toda a atenção acadêmica equivalente à relevância dele. Aliás, o nível de análise trabalhado não permitiu aprofundar diferenças internas aos projetos, como evidenciadas na renúncia de Guimarães. Com a contextualização e relevância expostas, a 
expectativa é estimular pesquisas que possam explorar, por exemplo, relações com CRPM e SM, atividades nos assuntos intra-Mercosul, e, como suscitou Andrés Malamud (CICLO, 2020), a extinção do ARGM ante debates de desintegração.

*Artigo recebido em 13 de julho de 2021, aprovado em 03 de novembro de 2021.

\section{REFERÊNCIAS}

ABC Color. En Brasil ya comparan el juicio político a Dilma con la crisis paraguaya del 2012. Disponível em: https://www.abc.com.py/edicion-impresa/politica/en-brasil-ya-comparanel-juicio-politico-a-dilma-con-la-crisis-paraguaya-del-2012-1465423.html. Acesso em: 31 jan. 2020.

$\mathrm{ABC}$ Color. Siguen las consultas para elegir nuevo representante de Mercosur. Disponível em: https://www.abc.com.py/edicion-impresa/politica/siguen-las-consultas-para-elegir-nuevorepresentante-de-mercosur-1549390.html. Acesso em: 31 jan. 2020.

ABC Color. Mercosur dejará en suspenso cargo de Alto Representante. Disponível em: https://www.abc.com.py/edicion-impresa/politica/mercosur-dejara-en-suspenso-cargo-de-altorepresentante-1574008.html. Acesso em: 31 jan. 2020.

$\mathrm{ABC}$ Color. Mercosur finalmente eliminó figura de alto representante. Disponível em: https://www.abc.com.py/edicion-impresa/politica/mercosur-finalmente-elimino-figura-de-altorepresentante-1615865.html. Acesso em: 26 mar. 2019.

ACTIS, Esteban. Brasil y sus pares sudamericanos de la "Alianza del Pacífico": Divergencias regionales en las opciones nacionales e internacionales. Relaciones Internacionales, vol. 23, $\mathrm{n}$. 46, p. 71-87, jan.-jun. 2014.

ÁlVAREZ, Chacho; PEYRANI, Julia. Los Caminos de la Integración: situación actual, complementación y proyección de los distintos organismos de la integración. Série Aportes, n. 12, p. 1-16, nov. 2011.

ARSLANIAN, Regis Percy. O Mercosul, do Tratado de Assunção até hoje. In: WEHLING, Arno; PIMENTEL, José Vicente de Sá (Ed.). A América do Sul e a integração regional. Brasília: FUNAG, 2012. p. 85-92.

BARTESAGHI, Ignacio. La encrucijada de la política exterior del Uruguay: ¿el Mercosur, la Alianza del Pacífico o ambas? In: Congresso Anual de la AMEI: anais de la Asociación Mexicana de Estudios Internacionales, 2013, p. 1-38.

BARTESAGHI, Ignacio; PEREIRA, María Eugenia. La Cohesión Regional en los Procesos de Integración en América Latina y el Caribe. Journal of Technology Management \& Innovation, vol. 11, n. 1, p. 93-101, 2016.

BIANCO, Viviane Melo. O papel do alto representante na construção de uma política externa comum nos processos de integração: uma análise comparada entre a União Europeia e o Mercosul. Revista do Programa de Direito da União Europeia, n. 5, p. 31-44, 2015. 
BIZZOZERO, Lincoln. El MERCOSUR en la segunda década del siglo XXI: bases y alcances del regionalismo estratégico. Sociedad y Discurso, n. 24, p. 69-89, 2013.

BIZZOZERO, Lincoln; RODRÍGUEZ, Damián. Un cuarto de siglo de Mercosur: alcances sudamericanos y debates periféricos. Aldea Mundo, n. 40, p. 19-28, jul.-dez. 2015.

BRICEÑO RUIZ, José. Las teorías de la integración regional: más allá del eurocentrismo. Bogotá: Centro de Pensamiento Global, 2018.

BONAVINO, Irina. El ingreso de Venezuela al Mercosur: ideología versus pragmatismo. Disponível em: http://covri.com.ve/wp-content/uploads/2015/10/NT5-MERCOSUR.pdf. Acesso em: 31 jan. 2020.

CABALLERO, Sergio. Brasil y la región: una potencia emergente y la integración regional sudamericana. Revista Brasileira de Política Internacional, vol. 54, n. 2, p. 158-172, 2011.

CABALlERO, Sergio. Mercosur, the Role of Ideas and a More Comprehensive Regionalism. Colombia Internacional, n. 78, p. 127-144, mai.-ago. 2013.

CARNEIRO, Patrícia Helena dos Santos. Uma avaliação crítica do processo de integração do Mercosul, à luz dos seus antecedentes, instrumentos e relações externas, em especial com a União Europeia. Santiago de Compostela. Tese (Doutoramento em Direito). Universidade de Santiago de Compostela, 2007.

CARTACAPITAL. Brasileiro deixa cargo de Alto Representante Geral do Mercosul. Disponível em: https://www.cartacapital.com.br/mundo/brasileiro-deixa-cargo-de-altorepresentante-geral-do-mercosul/. Acesso em: 29 jan. 2020.

CHAMORRO, Victor. Acuerdo comercial Mercosur - Unión Europea: Hubo avances en Montevideo. Disponível em: http://quorumdigital.uy/acuerdo-comercial-mercosur-unioneuropea-hubo-avances-en-montevideo/. Acesso em: 28 jan. 2019.

CICLO de Seminários de RI - $2^{\mathrm{a}}$ edição: "Processos de integração regional no mundo pós-pandemia". [S. l.: s. n.], 2020. 1 vídeo ( $1 \mathrm{~h} 34 \mathrm{~min} 7 \mathrm{~s})$. Publicado pelo canal ABCP. Disponível em: https://www.youtube.com/watch?v=9YqMIeeJyvw. Acesso em: 24 ago. 2020.

CLEMENTE, Isabel. Cooperación descentralizada en Mercosur: el caso de las unidades subnacionales en la frontera Uruguay-Brasil. In: Congresso Internacional FoMerco: anais eletrônicos. Salvador: FoMerco, UFBA, UNEB, 2017. p. 1-17.

DESIDERÁ, Walter Antonio. O Brasil e o Mercosul no governo Dilma (2011-2016). Anuario de la Integración Regional de América Latina y el Gran Caribe, vol. 14, p. 117-137, 2017.

DESIDERÁ, Walter Antonio. O Brasil, a América do Sul e a cooperação sul-sul. In: RAMANZINI JÚNIOR, Haroldo; AYERBE, Luis Fernando (Org.). Política externa brasileira, cooperação sul-sul e negociações internacionais. 1. ed. São Paulo: Cultura Acadêmica, 2015. p. 211-249.

DIARIO VICTORIA. Tras las declaraciones de Macri, Mercosur descarta sanciones para Venezuela. Disponível em: http://diariovictoria.com.ar/tras-las-declaraciones-de-macrimercosur-descarta-sanciones-para-venezuela/. Acesso em: 31 jan. 2020.

DIAS, Vanda Amaro. Integração regional no espaço pós-soviético: uma análise da política externa russa. JANUS 2015-2016: anuário de relações exteriores, n. 17, p. 120-121, nov. 2015. 
EFE. Autoridad Mercosur cree que habrá consenso en traspaso de mando a Venezuela. Disponível em: http://www.2001.com.ve/en-la-agenda/134757/autoridad-mercosur-cree-quehabra-consenso-en-traspaso-de-mando-a-venezuela.html. Acesso em: 1 fev. 2019.

EFE. El Mercosur decide suprimir la figura de su Alto Representante General. Disponível em: $\quad$ https://www.lavanguardia.com/politica/20170606/423217173341/el-mercosur-decidesuprimir-la-figura-de-su-alto-representante-general.html. Acesso em: 26 mar. 2019.

EFE. No hay rupturas en Mercosur tras dichos de Macri, afirman. Disponível em: https://www.hoy.com.py/nacionales/no-hay-rupturas-en-mercosur-tras-dichos-de-macriafirman. Acesso em: 31 jan. 2020.

ESPINO, Alma. Work and Employment in Mercosur from a Gender Perspective: Challenges and Public Policies. In: BIANCULLI, Andrea C.; RIBEIRO HOFFMANN, Andrea. Regional Organizations and Social Policy in Europe and Latin America: A Space for Social Citizenship?. 1. ed. Basingstoke: Palgrave Macmillan, 2016. p. 139-161.

FCES. Documento do FCES do MERCOSUL sobre a necessidade de fortalecimento do bloco de integração regional. Disponível em: https://documentos.mercosur.int/simfiles/docreunionanexos/73701 FCES 2019 ACTA02 ANE 03 ES DocumentoFortalecimientoMercosur.pdf. Acesso em: 1 fev. 2019.

FIGUEIREDO, Janaína. Alto representante-geral do Mercosul renuncia. Disponível em: https://oglobo.globo.com/mundo/alto-representante-geral-do-mercosul-renuncia-5342170.

Acesso em: 26 mar. 2019.

G1. Ivan Ramalho é nomeado presidente do conselho do BNDES. Disponível em: http://g1.globo.com/economia/noticia/2015/02/ivan-ramalho-e-nomeado-presidente-doconselho-do-bndes.html. Acesso em: 29 jan. 2020.

GIACALONE, Rita Ana. Principios económicos y narrativas políticas de las propuestas de reconfiguración del orden regional latinoamericano. In: MELLADO, Noemi Beatriz (Coord.; Ed.); SACA, Juan Carlos Fernández (Ed.). Desafíos para el regionalismo latinoamericano en el contexto internacional del siglo XXI. 1. ed. Antiguo Cuscatlán: Delgado, 2017. p. 51-76.

GIACOBONE, Gabriel. Del MERCOSUR comercial al MERCOSUR social: rupturas y continuidades. Informe Integrar, n. 95, p. 2-16, fev. 2016.

GRANATO, Leonardo. A integração na América do Sul em discussão nos governos do Brasil e da Argentina (2003-2010). Rio de Janeiro. Tese (Doutorado em Economia Política Internacional). Universidade Federal do Rio de Janeiro, 2014.

GUIMARÃES, Samuel Pinheiro. Relatório ao Conselho de Ministros. Disponível em: https://www2.camara.leg.br/atividade-legislativa/comissoes/comissoes-

mistas/cpcms/publicacoeseeventos/relatorio-ao-conselho-de-ministros. Acesso em: 29 jan. 2020.

INFORME INDUSTRIAL. Cambios en el SELA y en el Mercosur. Disponível em: http://www.informeindustrial.com.ar/verNota.aspx?nota=Cambios\%20en\%20el\%20SELA\%20y\% 20en\%20el\%20Mercosur 1247. Acesso em: 1 fev. 2020.

LA DIARIA. El huevo de la serpiente. Disponível em: https://ladiaria.com.uy/articulo/2015/7/el-huevo-de-la-serpiente/. Acesso em: 31 jan. 2020.

LA DIARIA. Paraguay confirmó eliminación del cargo de alto representante del Mercosur. Disponível em: https://ladiaria.com.uy/articulo/2017/3/paraguay-confirmoeliminacion-del-cargo-de-alto-representante-del-mercosur/. Acesso em: 31 jan. 2020. 
LEITE, Maria Luísa Telarolli de Almeida. O Acordo do Aquífero Guarani e a ótica da integração regional. São Paulo. Dissertação (Mestrado em Relações Internacionais). Programa Interinstitucional de Pós-Graduação em Relações Internacionais San Tiago Dantas, 2018.

LIMA, Uallace Moreira. Productive Integration in Mercosur and Its Implications for Korea's Economic Cooperation with the Region. In: KOREA INSTITUTE FOR INTERNATIONAL ECONOMIC POLICY (Org.). Studies in Comprehensive Regional Strategies Collected Papers (International Edition). Sejong: 2016. p. 143-194.

LIRA, Angelo Bruno Silva de. A procura da identidade: o Programa Escolas Interculturais de Fronteira como construção do comum. São Paulo. Dissertação (Mestrado em Relações Internacionais)-Programa Interinstitucional de Pós-Graduação em Relações Internacionais San Tiago Dantas. 2019.

MALAMUD, Andrés. El Mercosur: misión cumplida. Revista SAAP, vol. 7, n. 2, p. 275-282, nov. 2013.

MELLO, Beatriz Bandeira de; CORREAA, Sílvia Barros de Santana. Mercosul em debate: A política de integração regional nos governos Temer e Macri (2016-2018). In: MUÑOZ, Enara Echart; COELHO, André Luiz; VILLAMAR, Maria del Carmen Villarreal (Coord.). Sulatinidades: Debates do GRISUL sobre a América Latina. Rio de Janeiro: Périplos, 2019. p. 52-68.

MIRZA, Christian Adel; NASCONE, Mariano. Integración regional e inclusión social: los itinerarios del MERCOSUR. Revista do IMEA-UNILA, vol. 1, n. 2, p. 88-99, 2013.

MOLINA, Federico Rivas. Mercosul suspende a eleição direta dos deputados de seu Parlamento. Disponível

em: https://brasil.elpais.com/brasil/2019/04/16/internacional/1555374301 791741.html. Acesso em: 31 jan. 2020.

MONDELLI, Marcelo. MERCOSUR Continental y los espacios emergentes a nivel social. Pensamiento Próprio, vol. 43, p. 65-86. jan.-jun. 2016.

MONTEIRO, Tânia; PALACIOS, Ariel. Samuel Guimarães queixa-se de pouco apoio e deixa cargo no bloco. Disponível em: https://www2.senado.leg.br/bdsf/bitstream/handle/id/362793/complemento 1.htm. Acesso em: 29 jan. 2020.

NUEVO DIARIO. Mercosur podrá aplicar medidas en caso de ruptura institucional. Disponível em: http://www.nuevodiarioweb.com.ar/noticias/2016/03/27/15607-mercosur-podraaplicar-medidas-en-caso-de-ruptura-institucional. Acesso em: 31 jan. 2020.

PATRIOTA, Antonio de Aguiar. Discurso Inaugural. In: WEHLING, Arno; PIMENTEL, José Vicente de Sá (Ed.). A América do Sul e a integração regional. Brasília: FUNAG, 2012. p. 9-17.

PEIXOTO BATISTA, Juliana; PERROTTA, Daniela Vanesa. El Mercosur en el nuevo escenario político regional: más allá de la coyuntura. Desafíos, vol. 30, n. 1, p. 91-134, 2018.

PERROTTA, Daniela Vanesa; PORCELLI, Emanuel. Mercosur 25 años: desafíos en su nueva etapa. Márgenes, n. 2, p. 53-87, ago. 2016.

PESSOA, Luan Olliveira. As relações externas mercosulinas e o Alto Representante-Geral do Mercosul. Salvador. Dissertação (Mestrado em Relações Internacionais). Universidade Federal da Bahia, 2020. 
RAMOS, Hugo Daniel. El "nuevo MERCOSUR": cambios y continuidades institucionales a nivel regional en el período 2003-2013. Dimensões, n. 35, p. 470-493, 2015.

REQUIÃO, Roberto. Parecer do Senador Requião que cria o cargo de Alto RepresentanteGeral do Mercosul. Disponível em: http://www.robertorequiao.com.br/parecer-do-senadorrequiao-que-cria-o-cargo-de-alto-representante-geral-do-mercosul-2/. Acesso em: 18 fev. 2020.

RIBEIRO, Elisa de Sousa. Mercosul: sobre democracia e instituições. Brasília. Dissertação (Mestrado em Ciências Sociais). Universidade de Brasília, 2012.

SCHNEIDER, Fábio Böckmann. Parlamento do MERCOSUL e Parlamento Europeu: uma análise comparada. Porto Alegre. Tese (Doutorado em Ciência Política). Universidade Federal do Rio Grande do Sul, 2015.

SCOFIELD, Gilberto. Mercosul aprova a criação do cargo de alto representante. Disponível em: https://oglobo.globo.com/politica/mercosul-aprova-criacao-do-cargo-de-alto-representante2908891. Acesso em: 29 jan. 2020.

VENTURA, Deisy de Freitas Lima, ONUKI, Janina; MEDEIROS, Marcelo de Almeida. (Coords.). Internalização das normas do Mercosul. Brasília: Ministério da Justiça, 2012.

ZELICOVICH, Julieta. Juntos, pero no tanto: un recorrido por la agenda de negociaciones comerciales externas del MERCOSUR (1991-2015). Revista Integración y Cooperación Internacional, n. 21, p. 16-26, jul.-dez. 2015. 